\title{
Probabilistic framework for fatigue life assessment of notched components under size effects
}

\author{
Ding Liao a, Shun-Peng Zhu ${ }^{\mathrm{a}, \mathrm{b}, \mathrm{c}, *}$, Behrooz Keshtegar ${ }^{\mathrm{a}, \mathrm{d}}$, Guian Qian ${ }^{\mathrm{b}}$, Qingyuan Wang ${ }^{\mathrm{c}, \mathrm{e}, *}$ \\ ${ }^{a}$ School of Mechanical and Electrical Engineering, University of Electronic Science and Technology of China, Chengdu 611731, China \\ ${ }^{\mathrm{b}}$ State Key Laboratory of Nonlinear Mechanics (LNM), Institute of Mechanics, Chinese Academy of Sciences, Beijing 100190, China \\ ${ }^{\mathrm{c}}$ Key Laboratory of Deep Earth Science and Engineering, Ministry of Education, Sichuan University, Chengdu 610065, China \\ d Department of Civil Engineering, University of Zabol, Zabol, Iran \\ e School of Mechanical Engineering, Chengdu University, Chengdu 610006, China
}

A R T I C L E I N F O

\section{Keywords:}

Notch

Fatigue

Size effect

Failure probability

Life prediction

Weibull model

\begin{abstract}
A B S T R A C T
Structural integrity assessments with discontinuities are critical for ensuring operational life and reliability of engineering components. In this work, through combining with the generalized local model, a probabilistic framework is proposed for fatigue life assessment of notched components under size effects, in which the SmithWatson-Topper damage parameter is utilized to characterize the multiaxial stress state at the notch tip. In particular, an effective stress concept is introduced to characterize the inhomogeneous stress distribution within the notch region. Finally, experimental data of TA19 notched specimens with different scales are utilized for model validation and comparison, results show that the proposed framework yields acceptable correlations of predicted fatigue lives with experimental ones.
\end{abstract}

\section{Introduction}

In practice, engineering components generally fail at lower stress levels owing to irreversible microplastic deformation followed by crack propagation and final fracture of the whole component. The crack normally initiates at the regions with geometric discontinuities, also named as notches, often exist in the form of grooves, holes, keyways and fillets [1-5]. Notches have shown important influences on fatigue life of cyclically loaded parts for their stress raising effects, which raise enormous challenges to mechanical integrity and service reliability assessment in practice. However, according to the functional demands for connection, transmission, assembly etc., macroscopic notches are virtually inevitable in reality [6-11]. In addition, another important effect which usually appear in pairs with notches is the size effect [12-17]. Due to time and cost considerations as well as restrictions on testing equipment, fatigue assessment of large-scale structures is usually derived from experimental data of small-scale specimens. Consequently, a proper transfer from small specimens to large-scale structures requires the consideration of both size and stress-gradient induced notch effects $[18,19]$. For the case of aero engine integrity assessment, like the gas turbine bladedisc attachments of different scales, a model combing notch effect with size effect usually make the analogy analysis possible, which may avoid repetitive work and reduce costs from large-scale or full-scale testing.
In general, geometry caused stress concentration contributes to inhomogeneous stress distribution of engineering components. Whereas domains near the surface quickly reach yield strength and are therefore plastically strained, neighbouring materials that are less stressed will support the highly stressed volume (HSV) thus shielding it [2028]; therefore, traditional methods which only considers critical points no longer serve notch effect. For the notch effect, various empirical formulas have been developed to establish the relationship between the observed fatigue limit and the expectable strength of smooth specimens. However, few of them hold physical backgrounds and they normally present considerable scatters when applied to diverse materials [29]. To provide more accurate descriptions, series of models have been developed, including the stress gradient-based approaches [7], HSVbased approaches [30], critical distance-based methods [31,32] and weighting control parameter-based methods [33], their schematic diagram is shown in Fig. 1. Among them, weighting control parametersbased methods, including averaging local strain energy density approach [6,34], energy field intensity approach [26], stress field intensity approach [35] and effective stress method [36], seemed to provide reasonable description of contributions from the materials insides the effective volume to its fatigue process. Recently, Liao et al. [37] recalls recent developments and achievements in notch fatigue analysis of metals, which provides a reference for further research on notch fatigue

\footnotetext{
* Corresponding author.

E-mail addresses: liaoding@std.uestc.edu.cn (D. Liao), zspeng2007@uestc.edu.cn (S.-P. Zhu), bgar@uestc.edu.cn (B. Keshtegar), qianguian@imech.ac.cn (G. Qian), wangqy@scu.edu.cn (Q. Wang).
} 


\begin{tabular}{|c|c|}
\hline \multicolumn{2}{|c|}{ Nomenclature } \\
\hline \multicolumn{2}{|l|}{ Symbols } \\
\hline$b$ & fatigue strength exponent \\
\hline$c$ & fatigue ductility exponent \\
\hline E & Young's modulus \\
\hline$K^{\prime}$ & cyclic strength coefficient \\
\hline$n^{\prime}$ & cyclic strain hardening exponent \\
\hline$P_{\text {int }}$ & integrated probability of failure \\
\hline$S_{g}$ & distance of persistent slip bands in the failing grain \\
\hline$V$ & normalized variable of the Castillo-Canteli model \\
\hline$\beta$ & Weibull shape parameter \\
\hline$\varepsilon_{f}^{\prime}$ & fatigue ductility coefficient \\
\hline$\varepsilon_{n, a}$ & $\begin{array}{l}\text { maximum principle strain amplitude on the critical } \\
\text { plane }\end{array}$ \\
\hline$\lambda$ & Weibull location parameter \\
\hline$\rho^{*}$ & $\begin{array}{l}\text { critical distance of line method of critical distance ap- } \\
\text { proach }\end{array}$ \\
\hline$\sigma_{b}$ & ultimate tensile strength \\
\hline$\sigma_{f}^{\prime}$ & fatigue strength coefficient \\
\hline$\sigma_{L M}$ & $\begin{array}{l}\text { effective stress of line method of critical distance ap- } \\
\text { proach }\end{array}$ \\
\hline$\sigma_{P M}$ & $\begin{array}{l}\text { effective stress of point method of critical distance ap- } \\
\text { proach }\end{array}$ \\
\hline$\sigma_{\text {von }}^{e l}$ & elastic Huber-Mises equivalent stress \\
\hline$x^{2}$ & elasto-plastic relative stress gradient \\
\hline$B$ & asymptote of the threshold value of lifetime \\
\hline C & asymptote of the fatigue limit \\
\hline GP & generalized parameter \\
\hline$N_{f}$ & fatigue lifetime \\
\hline$P_{\text {fail }}$ & probability of failure \\
\hline$S_{\text {eq }}$ & equivalent size \\
\hline$S_{\text {ref }}$ & reference size \\
\hline$V_{x \%}$ & volume of highly stressed volume approach \\
\hline$\delta_{\text {ref }}$ & Weibull scale parameter \\
\hline$\varepsilon_{a}$ & strain amplitude \\
\hline$\eta$ & stress triaxiality \\
\hline$v$ & Poisson's ratio \\
\hline$\sigma_{0.2}$ & $0.2 \%$ offset yield stress \\
\hline$\sigma_{e f f}$ & effective stress \\
\hline$\sigma_{H}$ & hydrostatic stress \\
\hline$\sigma_{n, \max }$ & maximum normal stress on the critical plane \\
\hline$\sigma_{\text {von }}$ & Huber-Mises equivalent stress \\
\hline$\sigma_{x \%}$ & effective stress of highly stressed volume approach \\
\hline$\chi^{*}$ & elastic relative stress gradient \\
\hline APDL & ANSYS ${ }^{\circledR}$ parametric design language \\
\hline $\mathrm{CDF}$ & cumulative distribution function \\
\hline EFCDF & experimental failure cumulative distribution function \\
\hline GLM & generalized local model \\
\hline LCF & low cycle fatigue \\
\hline PPP & Poisson point process \\
\hline SWT & Smith-Watson-Topper \\
\hline $\mathrm{CCH}$ & central circular hole \\
\hline $\mathrm{CMB}$ & Coffin-Manson-Basquin \\
\hline FEA & finite element analysis \\
\hline HSV & highly stressed volume \\
\hline PFCDF & primary failure cumulative distribution function \\
\hline SEM & scanning electronic microscope \\
\hline TCD & theory of critical distance \\
\hline
\end{tabular}

analysis and promote the integration among different approaches for practice.

For size effect in fatigue, it has been subdivided into four categories [13]: a) statistical size effect-attributed to the probability of a higher

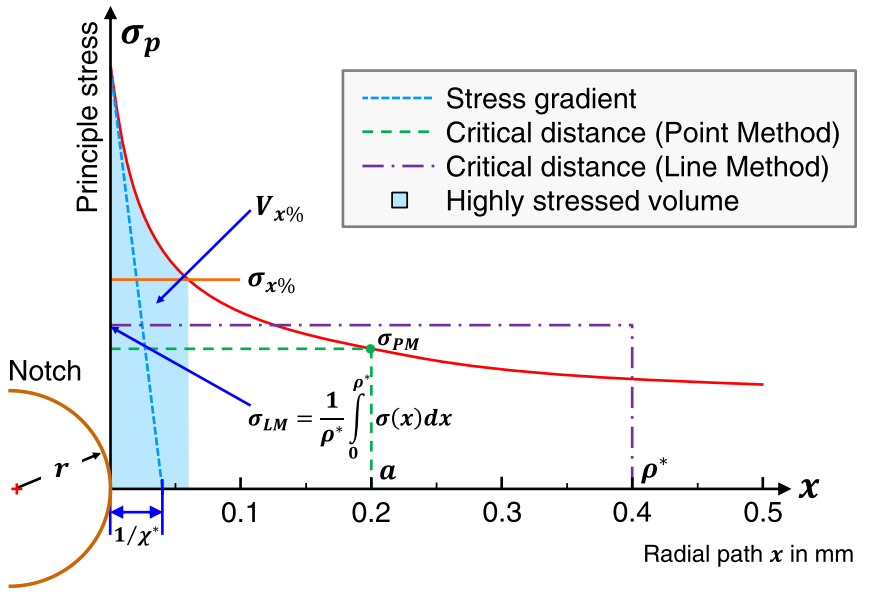

Fig. 1. Several concepts for notch fatigue assessment exemplified at a cross section.

defect bases in larger components, b) geometrical size effect-induced by diversiform stress distribution from different notch geometries, c) production size effect-due to the manufacturing technology (like residual stress), d) surface size effect-caused by the surface treatment technology (such as the roughness). However, in engineering practice, considering the size effect in its entirety is not always possible, since both production and surface size effects need sufficient data as well as reliable modelling method. Recently, increasing attention are mainly focused on statistical size effect or geometrical size effect or combined, as both of them present major influences on fatigue life, which will be detailed in Section 2. Until now, various methods accounting for size effects have been developed, including the weakest link model [38-40], HSV model [41], generalized local model (GLM) [42] and so on. However, efficient methods considering both notch and size effects are still lacking for engineering practice.

Recently, with the increasing attention on structural reliability and integrity, probabilistic fatigue models are merited as they include the effect of multiple uncertainty sources on fatigue lifetime [43-51]. In addition, compared with deterministic models, those which incorporate probabilistic factors could deduce fatigue lives of large structures from experimental databases of simple uniaxial tension-compression, torsion, bend or combination tests [19]. In conventional design processes, $P-S-N$ curves (series of $S-N$ curves corresponding to different survival rates $P$ to consider the dispersion of fatigue life), normally obtained by using the Weibull distribution, are commonly adopted. However, these practices overlook the influence of the reference parameter distribution relates to the geometry and dimensions of tested samples as well as loading conditions, which further forms barrier for coupling analysis of fatigue data from different experimental designs. Note from Calvente et al. [15] that on the premise of the effectiveness of the weakest link principle, the GLM can be applied for fatigue lifetime assessment based on the normalizing Weibull fatigue model [52]. Furthermore, fatigue crack initiation of engineering components based on reliability can be achieved, incorporating the influence of specimen geometry and scale as well as user defined damage parameter distribution. Coupling with the generalized local approach and the Weibull fatigue model, a novel methodology for probabilistic analysis of fatigue crack initiation considering size effect was established for fatigue lifetime evaluation of riveted joints.

In this work, by adopting elasto-plastic FE analysis, fatigue evaluation of notched components considering both notch and size effects (mainly the statistical and geometrical size effects) are investigated. Using the GLM concept proposed by Calvente et al. [15], a probabilistic framework is proposed for fatigue life assessment of notched components considering size effects. Specifically, the control damage parameter raised by Smith, Watson and Topper is chosen for notch fatigue 


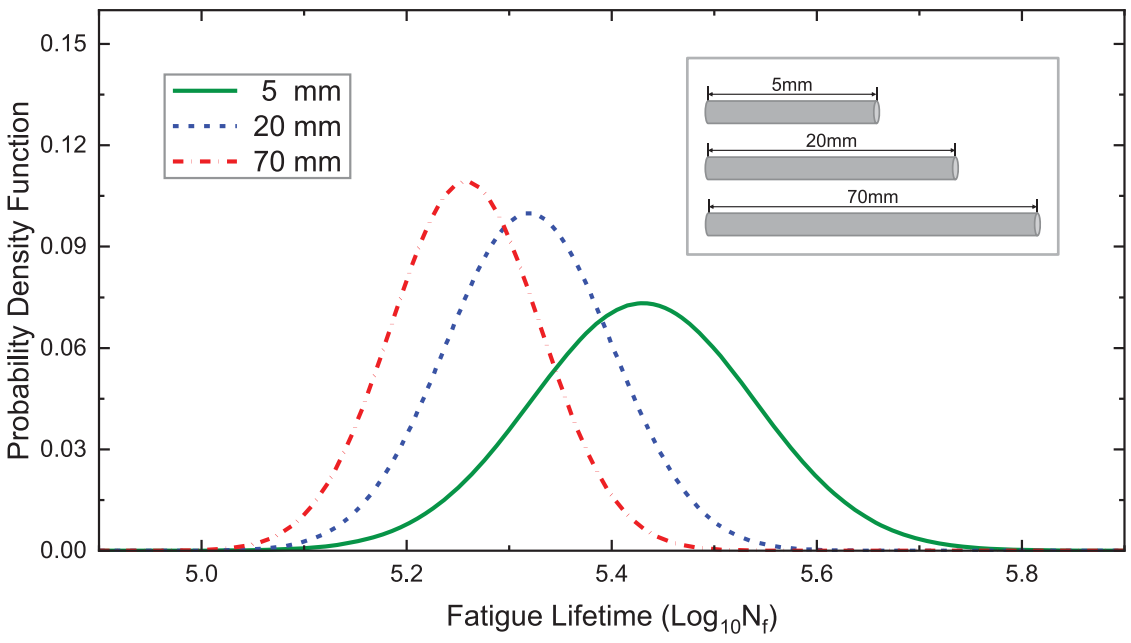

Fig. 2. Failure probability density function of cables of different lengths in [53]. analysis. In addition, an effective stress concept is utilized to characterize the influence of stress gradient on fatigue life. Remaining sections of this paper are outlined as follows: in Section 2, a short review on size effect in fatigue is presented; then, the extended generalized local model is introduced along with the Weibull probabilistic fatigue model and the effective stress approach; Section 4 provides application and validation of the proposed framework by experimental data of TA19 notched specimens with different scales; finally, main conclusions are drawn.

\section{Size effect in metal fatigue}

Size effect generally refers to the influence of size related messages on fatigue strength of components. As aforementioned, size effect can be classified into four types according to their sources. Among them, statistical and geometrical size effects have shown significant impacts on fatigue behaviour, which are also the focus of this study. As depicted in Fig. 2, for fatigue failure of structures with different scales, the statistical size effect works independently as the global stress is uniformly distributed. In experiments performed by Heckel et al. [53], cables with same radius but different lengths were tested under equal uniaxial loads. Note from Fig. 2, the longer the cable specimen is, the shorter its life is, which agrees well with the physical explanation of statistical size effect: for a sample subjected to alternating fatigue loads, a certain number of microcracks will initiate within its volume; obviously, those who with larger volume normally have higher probability to present larger initiated cracks and ultimately contribute to lower fatigue limit [29]. In general, this phenomenon can also be explained with the weakest link concept $[54,55]$. However, this rule may not serve all materials. Recently, in a research conducted by Zhu et al. [19], three sets of smooth 30NiCrMoV12 steel specimens with different specimen geometries have been tested; however, no significant differences in the lifetime of diverse material volumes were observed owing to the absence of independent features (defects and/or microstructural inhomogeneity) that able to trigger the failure.

Geometrical size effect comes into picture with discontinuous geometric characteristics, which depends on the stress gradient and can be investigated using the linear elastic fracture mechanics theories [29]. Fig. 3 presents a case incorporates both geometrical and statistical size effects. These two notch specimens have uniform shapes, but different scales. Under equal nominal loads, the internal and external stress distributions for these two specimens are similar. In detail, they share same maximum and minimum stress and strain, and the field distribution of one specimen can be obtained by proportional scaling the distribution of the corresponding field of another specimen. It is universally known that the fatigue lifetime of the smaller structure will be longer than the larger one. From the global perspective, the number of defects increases proportionately with the volume, thus the extrapolation between fatigue lifetime of specimens with different scales but similar geometry can be achieved by only considering statistical size effect. However, if considering this issue from a different perspective, this conclusion might be not reasonable. On one hand, supposing that the fatigue starts form the surface, and the materials within a certain distance from the surface to the interior contribute to fatigue failure, just as the theory of critical distance (TCD) [31]. Evidently, the averaging stress in the same length of the large specimen will be higher than that of small one, which leads to shorter fatigue lifetime. Meanwhile, the dispersion of the fatigue lifetime also increases by increasing the cable length. On the other hand, as pointed out by Makkonen [29], assuming that there is an initiated crack of depth $a_{0}$ with same distance from the surface. Fig. 3 shows a comparison of stress distribution between notch specimens with different scales, it can be found that the stress at the larger specimen- $\sigma_{1}$ is higher than the smaller one- $\sigma_{2}$, which means the stress intensity factor of the large specimen will also be larger as it shows a linear relation with stress. Therefore, the critical crack depth of larger specimen will be smaller which leads to a lower fatigue limit. The geometrical size effect can be roughly interpreted from the abovementioned two perspectives, which shows that when deducing the fatigue strength of notched specimens with same shapes but different scales, as seen from Fig. 3, both statistical and geometrical size effects should be taken into account.

To date, various methods have been put forward to describe the influence of size effect. Among them, some were raised from a deterministic viewpoint, such as fractal theory [56]; another from a probabilistic perspective, like the weakest link model [38] and HSV model [41]. However, most of them only consider statistical size effect and ignore the geometrical one, in particular during notch fatigue analysis. On the basis of Walker's mean stress correction model [57], Liu et al. [58] defined factors for stress gradient and dimensional size to depict the effects of stress gradient and scale on fatigue strength respectively, in which 6 parameters are included and hinders its application. Wang et al. [13] studied the statistical size effect on low cycle fatigue (LCF) of TA19 plates by integrating concepts of TCD and HSV, and provided a solution to predict the changing trend of fatigue lifetime, but whether it has considered both geometrical and statistical size effect remains further verification. Recently, Mäde et al. [21] developed a local probabilistic approach for prediction of LCF crack initiation lifetime based on the assumption of independent cracks occurring and the Coffin-Manson-Basquin (CMB) equation. By introducing Poisson point process (PPP), the methodology describes size effect and inhomogeneous strain field. In particular, a novel and more physical interpretation of the CMB parameters was given in which they are no longer fixed but geometry related values. Finally, a similar form, Eq. (1), of a commonly used formula, Eq. (2), 

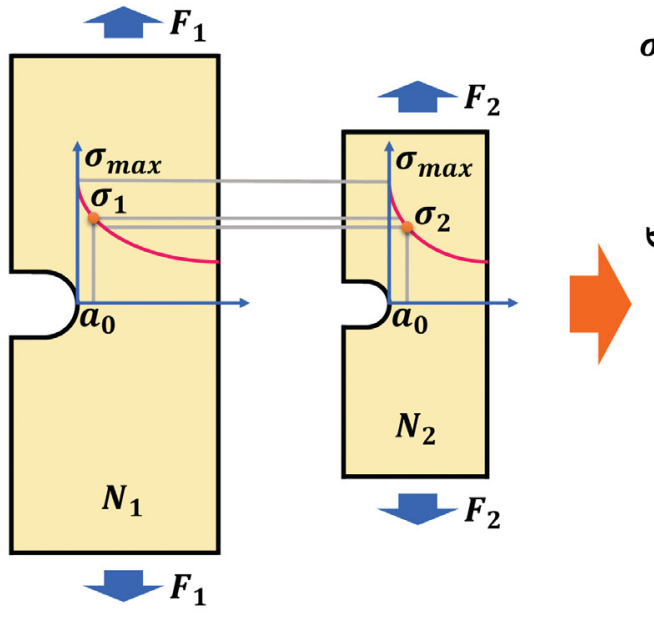

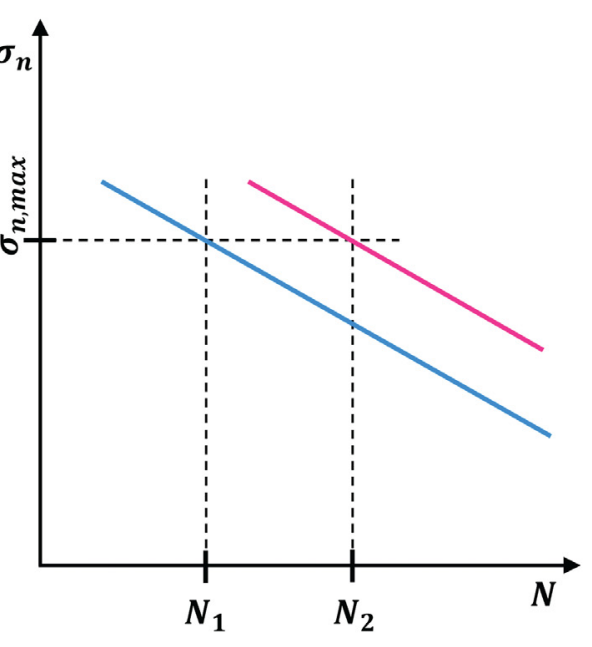

Fig. 3. Influence of joint geometrical and statistical size effects on fatigue life. about notch support factor $n_{\chi}$ is adopted to account for notch effect.

$n_{\chi}=1+\sqrt{S_{g} \cdot \chi^{*}}$

$n_{\chi}=1+A \cdot\left(\chi^{*}\right)^{k_{\chi}}$

where $S_{g}$ is the distance of persistent slip bands in the failing grain, $A$ and $k_{\chi}$ are material constants fitted by experiments, $\chi^{*}$ is the relative stress gradient under linear elastic FEA model and calculated at the surface only:

$\chi^{*}(x)=\frac{1}{\sigma_{v o n}^{e l}(x)} \cdot \frac{\partial \sigma_{v o n}^{e l}}{\partial x}$

in which $\sigma_{\text {von }}^{e l}$ is the elastic Huber-Mises stress. Combining with the CMB equation, fatigue lifetime at each integration point can be calculated by inverting the following expression:

$\frac{\varepsilon_{a}(x)}{n_{\chi}\left(\chi^{*}(x)\right)}=\frac{\sigma_{f}^{\prime}}{E}\left(2 N_{f}\right)^{b}+\varepsilon_{f}^{\prime}\left(2 N_{f}\right)^{c}$

where $E$ donates the Young's modulus, $\sigma_{f}^{\prime}, \varepsilon_{f}^{\prime}, b$ and $c$ are the axial fatigue property relevant parameters, $N_{f}$ represents the corresponding fatigue life. Finally, a probabilistic LCF assessment of the whole component can be conducted. However, as mentioned in the authors' previous research [4],Eq. (2) is not universal for all materials and applying a constant $\chi^{*}$ extracted from elastic field to elasto-plastic analysis still deserve comprehensive verification under more cases $[59,60]$.

Referring to the effective stress method, Wang et al. [61] developed a stress gradient modified critical distance method, which seems to be a promising approach to account for combined notch and size effect of different geometry features. Specifically, they pointed out that the relative stress gradient presents a major influence on the average spacing of fatigue striations [13], which affirms its important role in both notch and size effects evaluation. However, it only considers the average weighted stress on a single line, lacking of a comprehensive description of fatigue damage within the whole structure, which remains to be verified by a wide range of notch geometries before its practical application, thus more thorough investigations are still merited. Recently, through coupling the HSV concept with Weibull distribution, Ai et al. [30] established a probabilistic model which achieves transform of fatigue life distribution among specimens with different geometries, thus incorporates influences of both notch and size effects. Though it provides an effective and convenient strategy to consider both geometrical and statistical size effects on fatigue strength evaluation and acceptable correlations between model predictions and experimental results have been found, it is lacking of physics-of-failure description, namely there is no distinction between contributions of different material blocks inside the effective damage volume to the overall fatigue. To conclude, the conjoint analysis with notch effect (inhomogeneous stress distribution) is a key issue need to be resolved in research of size effect in metal fatigue.

To consider the varying distribution of the reference damage parameter over the structure, i.e. forecasting the fatigue lifetime of engineering components, a primary failure cumulative distribution function (PFCDF) concept was established by utilizing the GLM initially developed in researches about quasi-static failure of brittle and ductile materials [42], to enable reliable transference of fatigue characteristics collected from laboratory tests to the practical design. Combining the GLM with the Weibull probabilistic fatigue model, the uniqueness of the PFCDF can be enabled, Calvente et al. [15] developed a probabilistic methodology (just the Calvente's model for short) which achieves fatigue properties transferability from laboratory specimens to engineering components considering influence of geometries and dimensions. However, in the Calvente's model, the multiaxial stress state caused by geometric discontinuity as well as inhomogeneous stress distribution are ignored. According to this, methods accounting for these two factors have been integrated with the Calvente's model in Section 3.

\section{Probabilistic framework for notch fatigue analysis considering size effects}

\subsection{Weibull probabilistic fatigue model}

The Weibull probabilistic regression model was established by Castillo and Canteli [52], which was initially used combining with stress or strain-based approaches where the $S-N$ and $\varepsilon-N$ fields are expressed as percentiles, hyperbolic curves with equal failure probability. Specifically, it shows superiority to be employed in combination with arbitrary generalized fatigue parameters [62,63], which expands its application scope. Thus, the probabilistic generalized damage field for a generalized parameter $(G P)$ can be formulated as:

$P_{\text {fail }}=1-\exp \left[-\left(\frac{V-\lambda}{\delta_{\text {ref }}}\right)^{\beta}\right]$

s.t. $V=(\ln G P-C)\left(\ln N_{f}-B\right)$ where $\lambda, \delta_{r e f}, \beta$ are the Weibull location, shape and scale parameters, respectively; $V$ donates the normalized variable ensuring the $G P-N$ field to be degenerated into a simple cumulative distribution function (CDF); $B$ and $C$ respectively represents asymptotes of the threshold value of lifetime and fatigue limit. The transformation from the CDF of reference specimens to that of another sized specimens, $S_{\text {new }}$, only needs using a new scale parameter structured as:

$\delta_{\text {new }}=\delta_{\text {ref }}\left(\frac{S_{\text {ref }}}{S_{\text {new }}}\right)^{1 / \beta}$ 

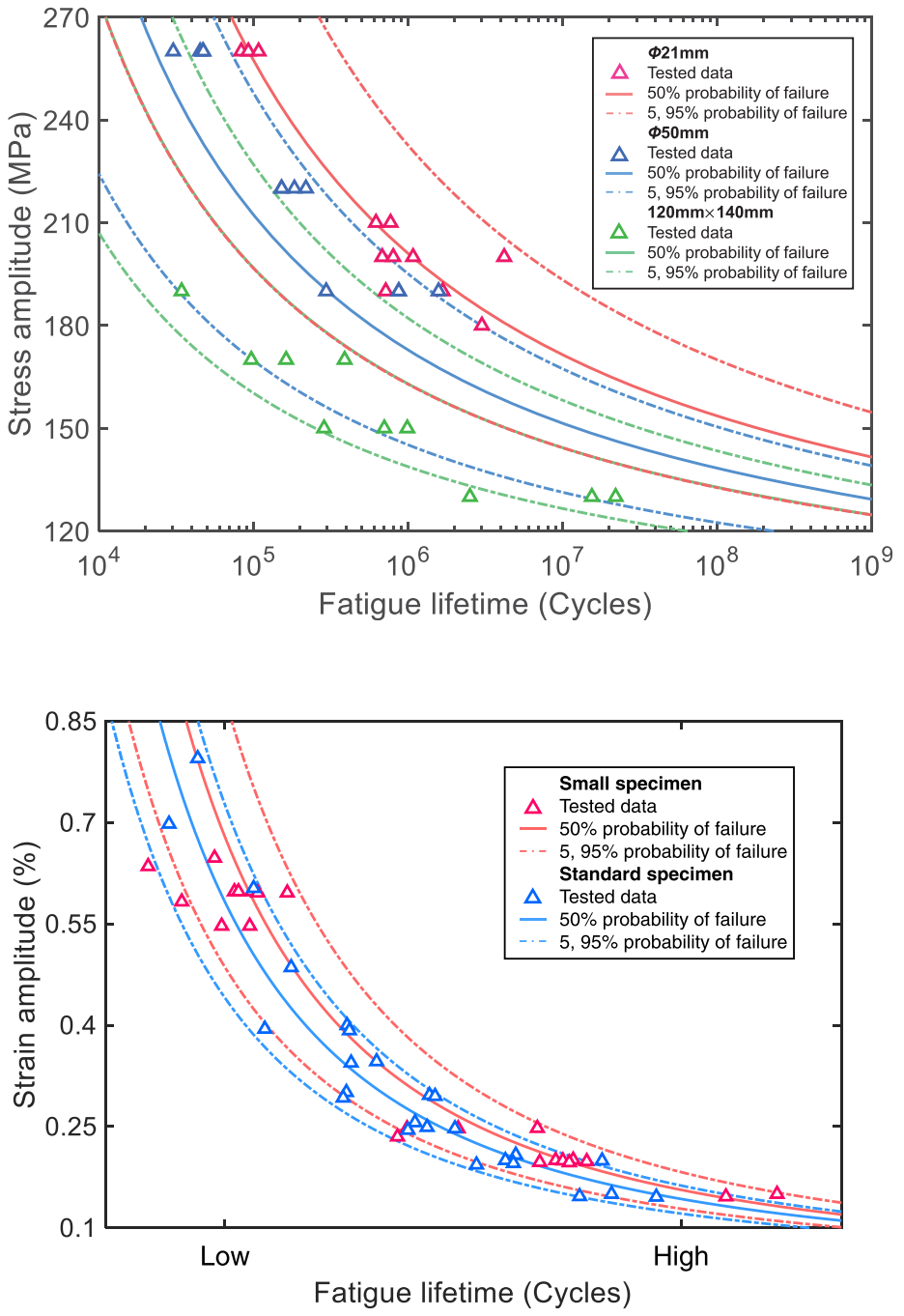

Fig. 5. Predicted fatigue lifetime of smooth RENE 80 nickel base superalloy specimens with different scales based on fatigue data of small specimens.

Combining Eq. (6) with Eq. (5), the probabilistic generalized damage field for the new sized specimen becomes:

$P_{\text {fail }}=1-\exp \left[-\frac{S_{\text {new }}}{S_{\text {ref }}}\left(\frac{V-\lambda}{\delta_{\text {ref }}}\right)^{\beta}\right]$

Herein, experimental data of smooth EN-GJS-400-18-LT ductile cast iron [64,65] and RENE 80 nickel base superalloy [59] specimens of different scales are collected for model validation. Note from Figs. 4 and 5, a good correlation is found between the predicted isoprobability failure curves and experimental data.

Although Eq. (4) enables a straightforward usage in those cases where the generalized parameters are homogenous distributed, distribution of damage parameters in mechanical components are generally nonuniform in engineering practice. Therefore, an extrapolation between smooth/notched specimens and actual components is desired. In view of the fact that the Weibull probabilistic fatigue model was developed based on the unique local maximum value of the reference fatigue parameter, if applying it to fatigue analysis of notched parts forcibly, the forecasting results will be unpredictable. According to this, Calvente et al. [15] combined this model together with the GLM to deal with those varying distribution cases.
Fig. 4. Predicted fatigue lifetime of smooth EN-GJS-400-18-LT ductile cast iron specimens with different scales based on fatigue data of $\emptyset 21 \mathrm{~mm}$ specimens.

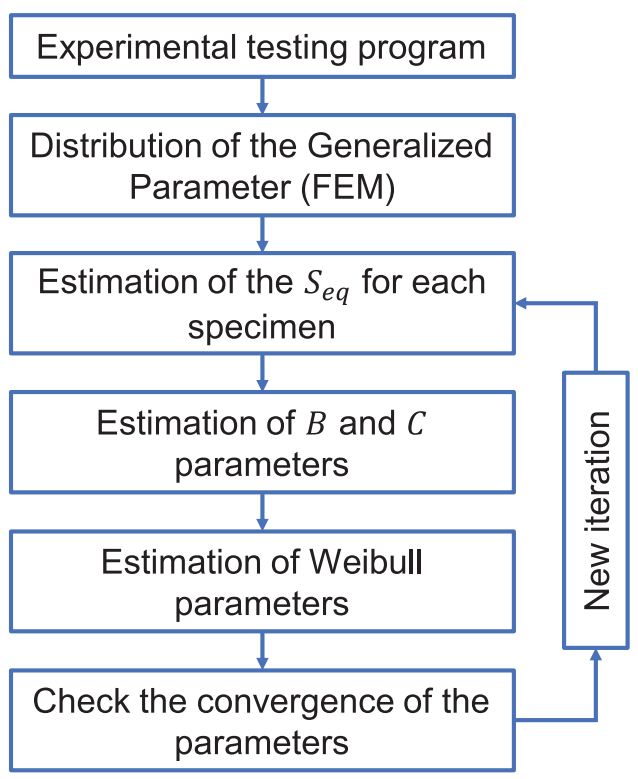

Fig. 6. Recursive process for determining the parameters of the PFCDF.

\subsection{Generalized local model and the Calvente's model}

As mentioned in [66], the primary objective of the GLM is to obtain the PFCDF as a referential material property, in which an iterative procedure is required to ensure the probability of failure for any finite elements to be evaluated coupling with a chosen GP and considering influences of shape, size and load conditions. In this manner, a reliable probabilistic failure evaluation of engineering components with different geometries under diversiform loading conditions can be realized. In detail, the iterative procedure for estimation of the five parameters of the PFCDF includes the following six steps: 1) conduct experimental testing program; 2) extract the distribution of the user defined damage parameter; 3) estimate the equivalent size for a test sample; 4) determine the asymptote relevant parameters $B$ and $C$; 5) calculate parameters of the Weibull distribution; 6) obtain the quality degree of the solution. Calvente et al. $[15,66]$ further summarized this procedure into a flow chart, see Fig. 6.

More details on this procedure can be referred to $[15,66]$. Herein, the third step which is closely related to the highlight of current work is elaborated. The third step focuses on the determination of the equivalent size, $S_{\text {eq, } i}$, which is defined as the size of the region uniformly undergoes 


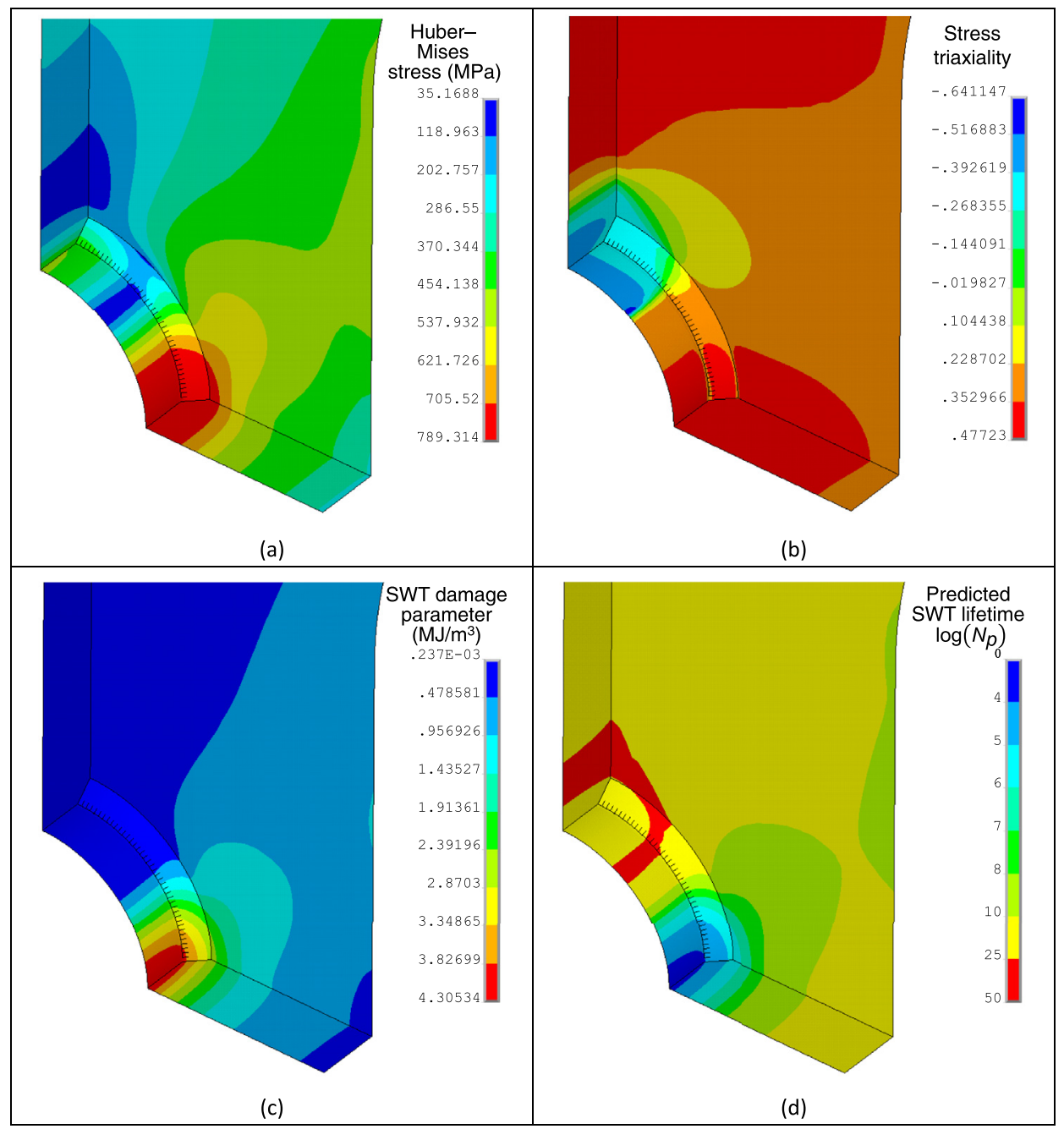

Fig. 7. Parameters distribution of $100 \%$ scale TA19 CCH specimens (with a $536.54 \mathrm{MPa}$ nominal net section stress, $1 / 8$ Model): a) HuberMises stress, b) stress axiality, c) SWT damage parameter, d) predicted SWT lifetime. (For geometry and dimensions of the $\mathrm{CCH}$ specimen, see Fig. 13). the maximum value of $G P$ until failure. In particular, it provides equal failure probability as the structure actual presenting an inhomogeneous $G P$ distribution, for instance, the distribution of damage parameter in Fig. 7 (c).

$S_{e q, i}=-\log \left(1-P_{i n t, i}\right) S_{r e f}\left[\frac{\delta_{r e f}}{V_{i}-\lambda}\right]^{\beta}$

where $P_{\text {int, } i}$ donates the integrated failure probability for the specimen numbered $i$.

$P_{i n t, i}=1-\prod_{j=1}^{n}\left(1-P_{f a i l, \Delta S_{i j}}\right)=1-\prod_{j=1}^{n}\left(\exp \left[-\frac{\Delta S_{i j}}{S_{r e f}}\left(\frac{V_{i j}-\lambda}{\delta_{r e f}}\right)^{\beta}\right]\right)$

where $\Delta S_{i j}$ and $V_{i j}$ are respectively the size and the normalized variable of the Castillo-Canteli model for subregion (element) numbered $j$. Note that $S_{\text {eq,i }}$ can't be calculated using Eqs. (8) and (9) in advance, during the first iteration, $S_{e q, i}$ is set as a value close to $80 \%$ of the real size to start the recursive procedure thus to accelerate the convergence rate of the algorithm [15].

\subsection{Proposed framework for notch fatigue analysis}

As described in Section 3.2, combining the Weibull probabilistic fatigue model with the GLM, Calvente et al. [15] transformed the experimental failure cumulative distribution function (EFCDF) to the PFCDF by introducing a recursive process. In such way, reliable probabilistic failure assessments of engineering components for arbitrary geometries and operating modes can be achieved irrespective of possible varying distributions presented by user defined GP. In summary, this methodology presents a promising strategy to deduce fatigue properties of complex mechanical structures from those parameters collected from experiments of specimens regardless of their shape, size as well as testing modes. However, as mentioned in Section 2, this method neglects the influence of multiaxial stress state and notch effect (which may also influence its consideration on geometrical size effect). In this regard, a probabilistic framework considering multiaxial stress and stress gradient based on the Calvente's model is established for notch fatigue analysis considering size effects.

When materials undergo different stress states, corresponding degrees of plastic deformation and stress concentration also vary, which contributes to diverse material fracture mechanism. In order to reflect material's complex stress states under external loads, the concept of stress triaxiality $\eta$ was introduced to describe the complexity of stress states $[67,68]$, which can be expressed as follow:

$\eta=\frac{\sigma_{H}}{\sigma_{v o n}}=\frac{\frac{1}{3}\left(\sigma_{1}+\sigma_{2}+\sigma_{3}\right)}{\sqrt{\frac{\left(\sigma_{1}-\sigma_{2}\right)^{2}+\left(\sigma_{2}-\sigma_{3}\right)^{2}+\left(\sigma_{3}-\sigma_{1}\right)^{2}}{2}}}$

where $\sigma_{H}$ donates the hydrostatic stress, $\sigma_{\text {von }}$ represents the HuberMises equivalent stress, $\sigma_{1}, \sigma_{2}$ and $\sigma_{3}$ are the three principal stresses, respectively. As depicted in Fig. 7 , although the applied load is uniaxial, owing to the geometrical discontinuities, a complex multiaxial stress field appears near the notch root region. 


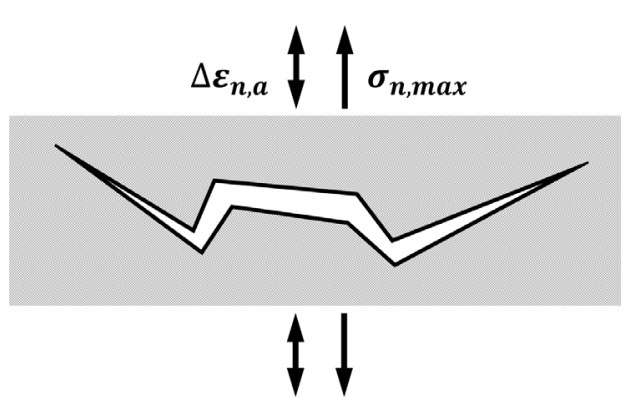

Fig. 8. Fracture mechanism of the SWT model.

Considering that TA19 central circular hole (CCH) specimens [13] are subjected to tensile dominant multiaxial fatigue loads, herein, the fatigue model developed by Smith, Watson and Topper (named as the SWT model), is introduced [69]. In the SWT model, the plane with maximum principle strain amplitude $\varepsilon_{n, a}$ is defined as the critical damage plane, and the damage parameter is calculated by the product of $\varepsilon_{n, a}$ and the maximum normal stress $\sigma_{n, \max }$ on this plane, see Fig. 8. In particular, the stress term is effective in describing non-proportional strengthening effect under multiaxial loads and mean stress effects [70].

$\varepsilon_{n, a} \sigma_{n, \max }=\frac{\left(\sigma_{f}^{\prime}\right)^{2}}{E}\left(2 N_{f}\right)^{2 b}+\varepsilon_{f}^{\prime} \sigma_{f}^{\prime}\left(2 N_{f}\right)^{b+c}$

Based on the Calvente's model, the generalized parameter is given by the SWT damage parameter, not the uniaxial strain range, i.e. GP in Eq. (5). In detail, it takes the advantage of the Weibull probabilistic fatigue model of being able to be employed together with arbitrary generalized fatigue parameters and the SWT model of being able to deal with those tensile dominant multiaxial fatigue cases. To prove the effectiveness of this improvement, a comparison between predicted fatigue lifetime of smooth TA19 titanium alloy and P355NL1 steel specimens based on the total strain range and the SWT damage parameter are respectively presented in Section 4. Another nonnegligible issue is the notch effect, which may be interpreted as inhomogeneous stress distribution or stress gradient effects. As depicted in Fig. 7 of [21], Mäde et al. pointed out that the shift of the Basquin curve [71,72] (including probabilistic one) from smooth specimen to notched one should be a combined action of notch and size effect. In addition, in a recent experiment conducted by Wang et al., see Figure 17 and Table 6 of [61], TA19 $\mathrm{CCH}$ specimens with different scales were tested. By employing scanning electronic microscope (SEM) technique, they studied correlations between stress gradient and crack propagation behaviour. In detail, the average fatigue striations widths for different scales of specimens under given loads were measured at sites within fatigue source region. According to their research, the average fatigue striation width decreases by the increasing the absolute stress gradient. In abovementioned works, the significant role of the notch effect is affirmed as well as the geometrical size effect.

As aforementioned, the SWT model is adopted to consider multiaxial stress which has shown its superiority in tensile dominant cases, and the next step is to characterize the notch effect. Then, how to provide a reasonable interpretation for the influence of stress gradient on fatigue? Wang et al. [61] provide a solution, that is to replace the maximum normal stress term with the effective stress concept. Effective stress approach is developed by Qylafku et al. [36,73-75] based on a consideration of the physical mechanism of fatigue initiation and, particularly, on the necessity for a physical volume in which the fatigue process can proceed. To consider the effect of the real elastic-plastic stress distribution on fatigue strength, Pluvinage [36] extended the formula of the relative stress gradient as:

$\chi(x)=\frac{1}{\sigma(x, \theta=0)} \cdot \frac{\partial \sigma_{y y}(x, \theta=0)}{\partial x}$

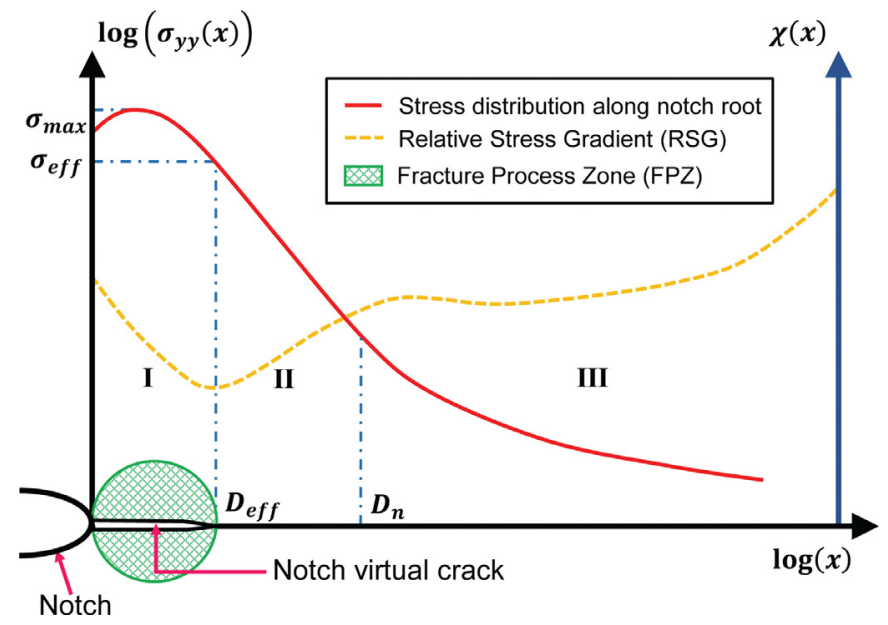

Fig. 9. Typical elastic-plastic stress and relative stress gradient distributions in the vicinity of an external notch.

In the effective stress approach, the relative stress gradient can reflect the contribution of stress at different locations within the damage zone to the overall fatigue by introducing a weight function. In particular, as shown in Fig. 9, Pluvinage et al. [73] divided the stress distribution in the vicinity of the notch root into three regions according to the distribution of stress and relative stress gradient at the notch tip.

As shown in Fig. 9, region I is the "high stress" region contains the maximum stress, which forms the effective damage zone of the effective stress approach, and its boundary $D_{e f f}$ is defined as the distance from the surface of the notch to the inside of the notch until its stress distribution reaches its first inflexion point (i.e. the first minimum value of the relative stress gradient). After setting the boundaries of the effective damage zone, Qylafku gave the expression of the effective stress:

$\sigma_{e f f}=\frac{1}{D_{e f f}} \int_{0}^{D_{e f f}} \sigma(x, \theta=0) \times \varphi(x, \chi(x)) d x$

where $\phi(x, \chi(x))$ is the weight function, and its expression is given as follow:

$\varphi(x, \chi(r))=1-|\chi(x)| \cdot x$

Compared with the stress field intensity approach, the effective stress approach is more convenient in determining the boundary of the effective damage zone, which greatly simplifies analysis process and provides a new solution for fatigue analysis of notched components. Through coupling the Calvente's model with the SWT model and effective stress concept, Eq. (9) can be rewritten as:

$P_{\text {fail }, i}=1-\prod_{j=1}^{n}\left(\exp \left[-\frac{\Delta S_{j}}{S_{r e f}}\left(\frac{\left(\ln \left(\varepsilon_{n, a} \sigma_{e f f}\right)-C\right)(\ln N-B)-\lambda}{\delta_{r e f}}\right)^{\beta}\right]\right)$

which provides an extension based on the generalized local model considering multiaxial stress and stress gradient.

From the abovementioned points, a general probabilistic framework for fatigue life assessment of notched components considering size effects is summarized as shown in Fig. 10.

\section{Model validation and application}

In order to verify the model prediction ability of the proposed probabilistic framework, fatigue data of smooth specimens manufactured from TA19 titanium alloy and P355NL1 steel under uniaxial loadings are utilized for model validation in Section 4.1, then notched specimens in Section 4.2. 


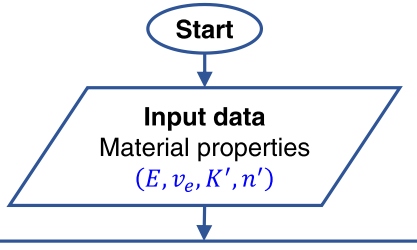

3D Elasto-plasticity FE analysis (Smooth specimens) KINH model, loads, fatigue lifetime, SWT damage parameter

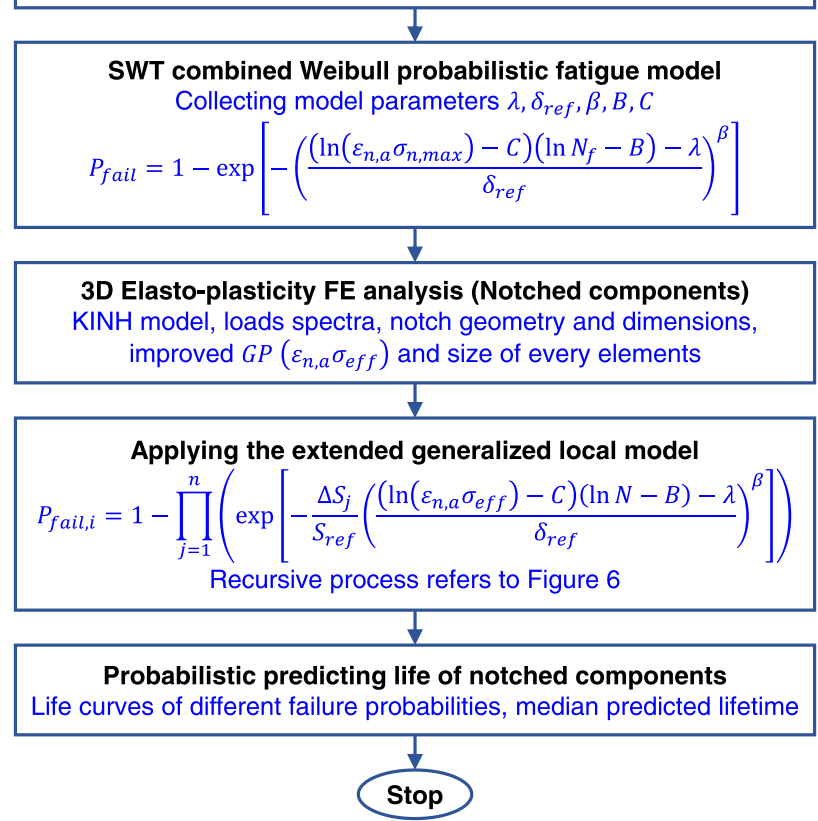

Fig. 10. Probabilistic framework for fatigue life assessment of notched components considering size effects.

Table 1

Mechanical properties for TA19 alloy and P355NL1 steel [76].

\begin{tabular}{llllll}
\hline Materials & $T\left({ }^{\circ} \mathrm{C}\right)$ & $E(\mathrm{GPa})$ & $v$ & $\sigma_{0.2}(\mathrm{MPa})$ & $\sigma_{\text {uts }}(\mathrm{MPa})$ \\
\hline TA19 alloy & 180 & 109.8 & 0.32 & 825 & 953 \\
P355NL1 steel & 20 & 205.2 & 0.275 & 418 & 568 \\
\hline
\end{tabular}

\subsection{Model validation with smooth specimens}

To demonstrate the effectiveness of the SWT model for probabilistic fatigue life prediction, experimental data of smooth TA19 titanium alloy [76] and P355NL1 steel are employed for model verification, material properties and load conditions as well as tested lives are tabulated in Tables 1-3.

Fig.s 11 and 12 plot a comparison between taking the uniaxial strain range and the SWT damage parameter as GP within the Weibull probabilistic fatigue model. To quantify the model prediction ability, an error index $\bar{E}$ is introduced to assess the deviation between $50 \%$ evaluated fatigue lives (i.e. red lines in Fig.s 11 and 12) and tested lives [13,32], in which the smaller $\bar{E}$ indicates more accurate predictions, see Table 4.

$E_{i}=\log \left(N_{50 \% p, i} / N_{t, i}\right)$

$\bar{E}=\frac{1}{n} \sum_{i=1}^{n}\left|E_{i}\right|$

\subsection{Model validation with notch specimens}

In this section, to apply the extended generalized local model to practical fatigue lifetime assessment, experimental data of TA19 CCH specimens with different scales [76] are utilized for model validation.

TA19 alloy (similar to the Ti-6242S alloy) presents excellent processing properties and weldability, and its maximum temperature for long-term operating is $500^{\circ} \mathrm{C}$ [77]. In experiments conducted by Wang et al. [76], all specimens were cut from an real compressor disc. Mechanical properties of TA19 alloy are listed in Table 1. Fatigue test data of smooth TA19 specimens have been provided in Table 2. More details about the experiments, including chemical composition, heat treatment processing, etc., can be referred to [76]. In addition, to investigate the impact of size effect on the LCF lifetime, as shown in Fig. 13, CCH specimens with different scales were manufactured. In detail, $80 \%, 60 \%$ and $40 \%$ scale specimen, the thickness, hole diameter as well as width of the test section were reduced to $80 \%, 60 \%$ and $40 \%$ of the $100 \%$-scale $\mathrm{CCH}$ specimens, see Table 5 .

In particular, there is a small difference between ratios of their chamfers, but the stress concentration factor $K_{t}$ of all $\mathrm{CCH}$ specimens with different scales are nearly equal, and they also present similar damage parameters distribution irrespective of their dimensional difference. Table 6 tabulated experimental data of $\mathrm{CCH}$ specimens with different scales under different load levels.

This section includes two parts, the first part is to evaluate fatigue life of $100 \%$ scale TA19 CCH specimens under different load levels by taking experimental data of smooth specimens as reference, another part is to deduce the fatigue lifetime of CCH specimens of varying scales.

Similar to the application of the Calvente's model [15], the analysis procedure of the extend generalized local model only get a small difference in obtaining the distribution of the generalized parameter, other steps in recursive process for determining the parameters of the PFCDF are same as those shown in Fig. 6. The PFCDF for the TA19 titanium alloy obtained by smooth specimens subjected to uniaxial loads taking the SWT damage parameter as GP has already been given in Fig. 12 (b) and the reference size $S_{\text {ref }}$, i.e. the central surface area of the smooth specimen is $706.858 \mathrm{~mm}^{2}$.

In detail, the first step is to determine the generalized parameter distribution is to extract full stress and strain responses of nodes on the surface; then search the critical plane of each node and apply the effective stress approach on the critical plane at the load substep with the peak nominal stress; finally, calculate the GP, i.e. $\varepsilon_{n, a} \sigma_{e f f}$, of each point and generate the generalized parameter distribution field within the whole structure. Following this procedure, Fig. 14 illustrates an example for calculating the effective stress at the notch tip. By collecting the stress data from FE analysis and fitting its relationship with the distance from the notch tip using a 10-order polynomial (in virtue of the symmetry, the critical plane must coincide with the minimum cross section area). Then, solving the derivative of the polynomial, and $\sigma_{\text {eff }}$ can be determined according to Eq. (13). Other analytical procedures are consistent with Fig. 6. Moreover, it deserves our attention that when employing Eq. (15), those elements not satisfying the condition of $\ln \left(\varepsilon_{n, a} \sigma_{e f f}\right)-C$ $>0$ should be removed/discarded, as it violates the assumption of the existence of a fatigue limit in the Weibull probabilistic fatigue model.

According to the load spectrum listed in Table 6, FE analysis of $100 \%$ scale TA19 CCH specimens are performed respectively using the multilinear kinematic hardening (KINH) rule. To ensure the computational accuracy, 2-order 20-node quadratic brick 3D elements Solid 186 is utilized and an element optimization process is carried out until the maximum stress convergences. In the light of the symmetry of the structure, only $1 / 8$ model is built, see Fig. 14. Through FE analysis, postprocessing relevant data using APDL command stream and then inputting the array containing GP and the size of each element into the iterative procedure, and then the solution process is complete. Finally, by setting the probability of failure $P_{\text {fail }}$ as $0.05,0.5,0.95$ respectively, as presented in Fig. 15, the predictions for failure probability curves are plotted by con- 
Table 2

Fatigue test data of smooth TA19 alloy at $180^{\circ} \mathrm{C}[76]$.

\begin{tabular}{llll}
\hline Maximum strain (\%) & Minimum strain (\%) & Number of specimens & Average fatigue life (Cycles) \\
\hline 1.60 & 0.16 & 2 & 2890 \\
1.40 & 0.14 & 3 & 12,685 \\
1.20 & 0.12 & 4 & 23,441 \\
1.00 & 0.10 & 3 & 133,809 \\
0.80 & 0.08 & 3 & 339,722 \\
\hline
\end{tabular}

Table 3

Fatigue test data of smooth P355NL1 steel.

\begin{tabular}{lllll}
\hline No. & Strain range (\%) & Strain ratio & Load frequency $(\mathrm{Hz})$ & Fatigue lifetime (Cycles) \\
\hline 1 & 3.00 & 0 & 0.133 & 77 \\
2 & 2.00 & 0 & 0.200 & 260 \\
3 & 1.50 & 0 & 0.266 & 503 \\
4 & 1.50 & 0 & 0.266 & 433 \\
5 & 1.50 & 0 & 0.266 & 511 \\
6 & 1.00 & 0 & 0.400 & 1625 \\
7 & 1.00 & 0 & 0.400 & 1133 \\
8 & 1.00 & 0 & 0.400 & 1280 \\
9 & 0.75 & 0 & 0.533 & 2440 \\
10 & 0.75 & 0 & 0.533 & 3300 \\
11 & 0.75 & 0 & 0.533 & 3565 \\
12 & 0.60 & 0 & 0.666 & 7805 \\
13 & 0.60 & 0 & 0.666 & 5700 \\
14 & 0.50 & 0 & 0.800 & 14,760 \\
15 & 0.50 & 0 & 0.800 & 14,197 \\
16 & 0.50 & 0 & 0.800 & 8520 \\
17 & 0.40 & 0 & 1.000 & 16,000 \\
\hline
\end{tabular}

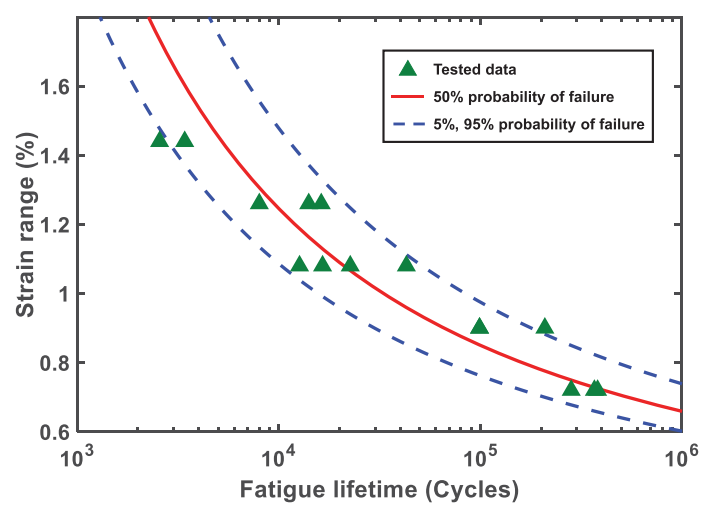

(a)

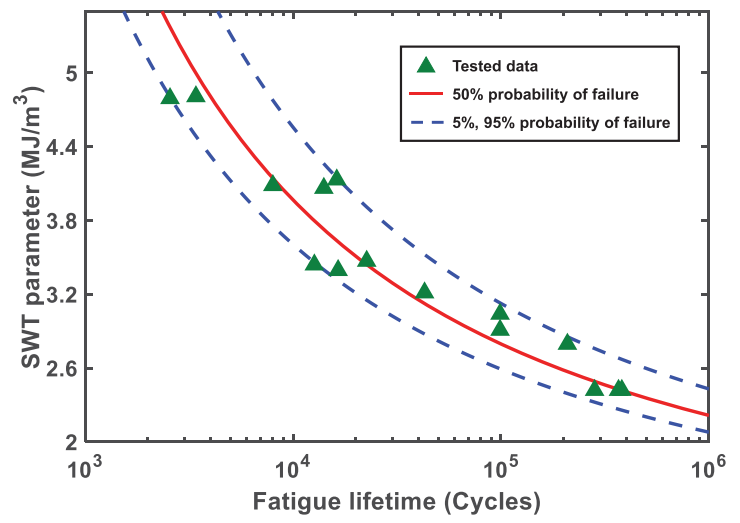

(b)

Fig. 11. Predicted fatigue lifetime of smooth TA19 alloy based on (a) the total strain range, (b) the SWT damage parameter.

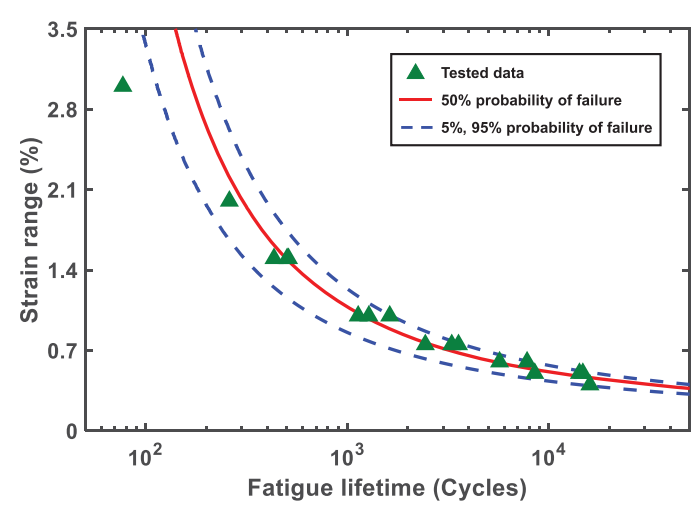

(a)

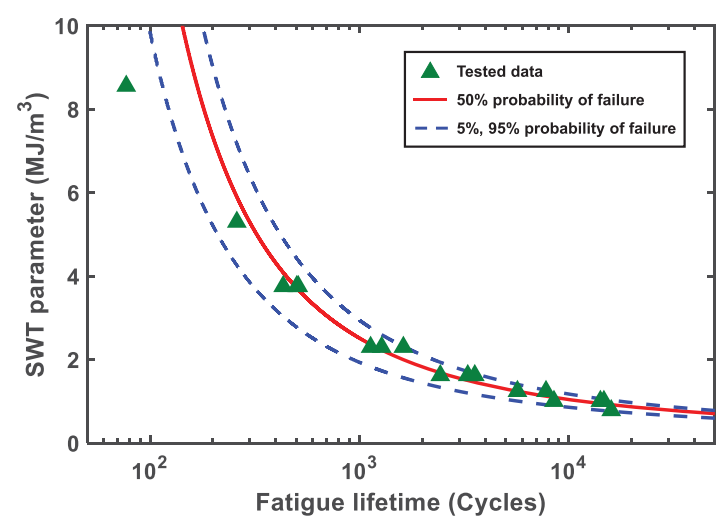

(b)

Fig. 12. Predicted fatigue lifetime of smooth P355NL1 steel based on (a) the total strain range, (b) the SWT damage parameter. 
Table 4

Average absolute predicted errors (\%).

\begin{tabular}{lll}
\hline Materials & Total strain range & SWT damage parameter \\
\hline TA19 alloy & 18.17 & 14.72 \\
P355NL1 steel & 10.33 & 9.85 \\
\hline
\end{tabular}

Note from Table 4, for the two materials, procedures coupling the SWT model generally show relatively better predictions than those with the total strain range. Therefore, in the following analysis, the SWT damage parameter is adopted as GP in Eq. (5).

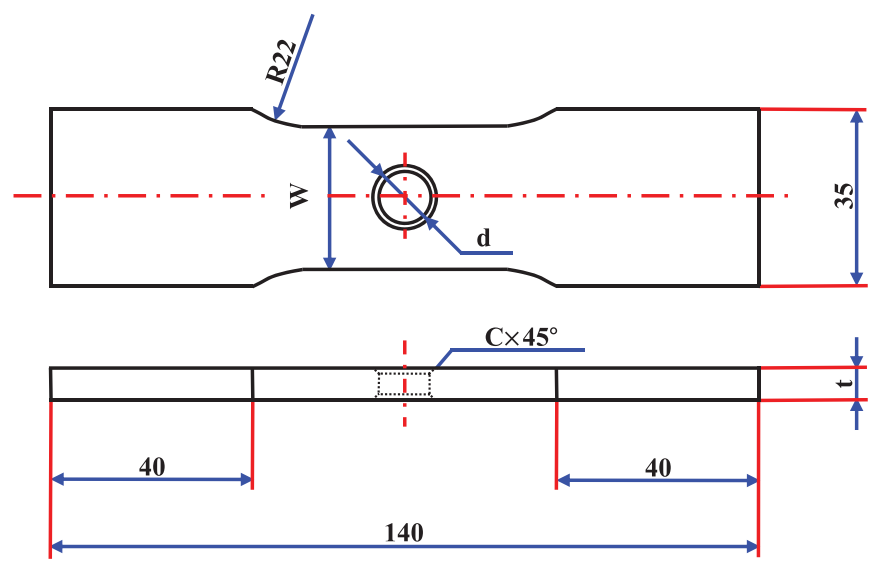

Fig. 13. Geometry and dimensions of $\mathrm{CCH}$ specimens with different notch scales (unit: $\mathrm{mm}$ ).

necting the predicted points of five load levels with smooth curves. By repeating abovementioned procedure, comparison of experimental and predicted probabilistic lifetimes for different scales of TA19 CCH specimens using the extended generalized local model are shown in Fig. 16.

Note from Figs 15 and 16, the calculated fatigue lives for failure probability equal to $50 \%$ are generally well correlated with the experimental fatigue lives for $\mathrm{CCH}$ specimens of TA19 alloy, which verifies the feasibility of extrapolating the fatigue life of notched parts by combining the extended generalized local model with fatigue data of smooth specimens. In addition, Table 7 provides a comparison between average absolute errors of different scales of $\mathrm{CCH}$ specimens using the proposed model and a novel model combining critical distance as well as HSV model developed by Wang et al. [13], shortened as LNV model, respec-
Table 5

Summary of the geometrical dimensions of $\mathrm{CCH}$ specimens with different scales [76].

\begin{tabular}{llllll}
\hline Scale $(\%)$ & $d(\mathrm{~mm})$ & $W(\mathrm{~mm})$ & $t(\mathrm{~mm})$ & $C(\mathrm{~mm})$ & $K_{t}$ \\
\hline 100 & 10.5 & 28.0 & 6.0 & 0.8 & 2.321 \\
80 & 8.4 & 22.4 & 4.8 & 0.6 & 2.336 \\
60 & 6.3 & 16.8 & 3.6 & 0.5 & 2.353 \\
40 & 4.2 & 11.2 & 2.4 & 0.3 & 2.357 \\
\hline
\end{tabular}

Table 6

Fatigue test data of LCF tests on CCH specimens at $180^{\circ} \mathrm{C}[76]$.

\begin{tabular}{llll}
\hline Scale (\%) & $\begin{array}{l}\text { Maximum nominal stress } \\
(\mathrm{MPa})\end{array}$ & $\begin{array}{l}\text { Number of } \\
\text { specimens }\end{array}$ & $\begin{array}{l}\text { Average fatigue life } \\
\text { (Cycles) }\end{array}$ \\
\hline 100 & 634.94 & 4 & 8078 \\
100 & 588.70 & 4 & 10,225 \\
100 & 536.54 & 5 & 20,062 \\
100 & 496.72 & 4 & 30,963 \\
100 & 450.73 & 4 & 35,604 \\
80 & 536.54 & 4 & 21,836 \\
60 & 536.54 & 4 & 22,505 \\
40 & 536.54 & 5 & 28,979 \\
\hline
\end{tabular}

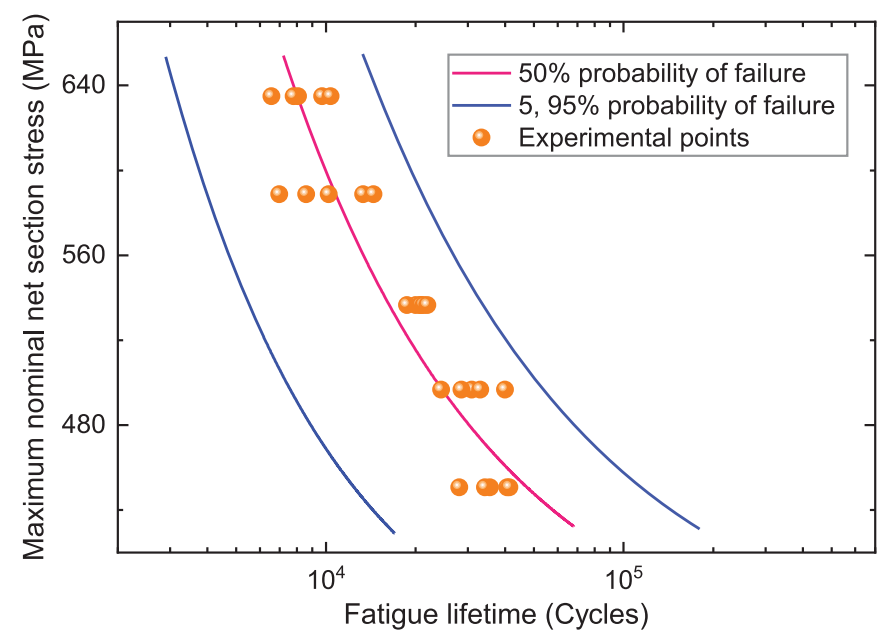

Fig. 15. Predicted $P-S-N$ curves for of $100 \%$ scale TA19 CCH specimens under different load levels.

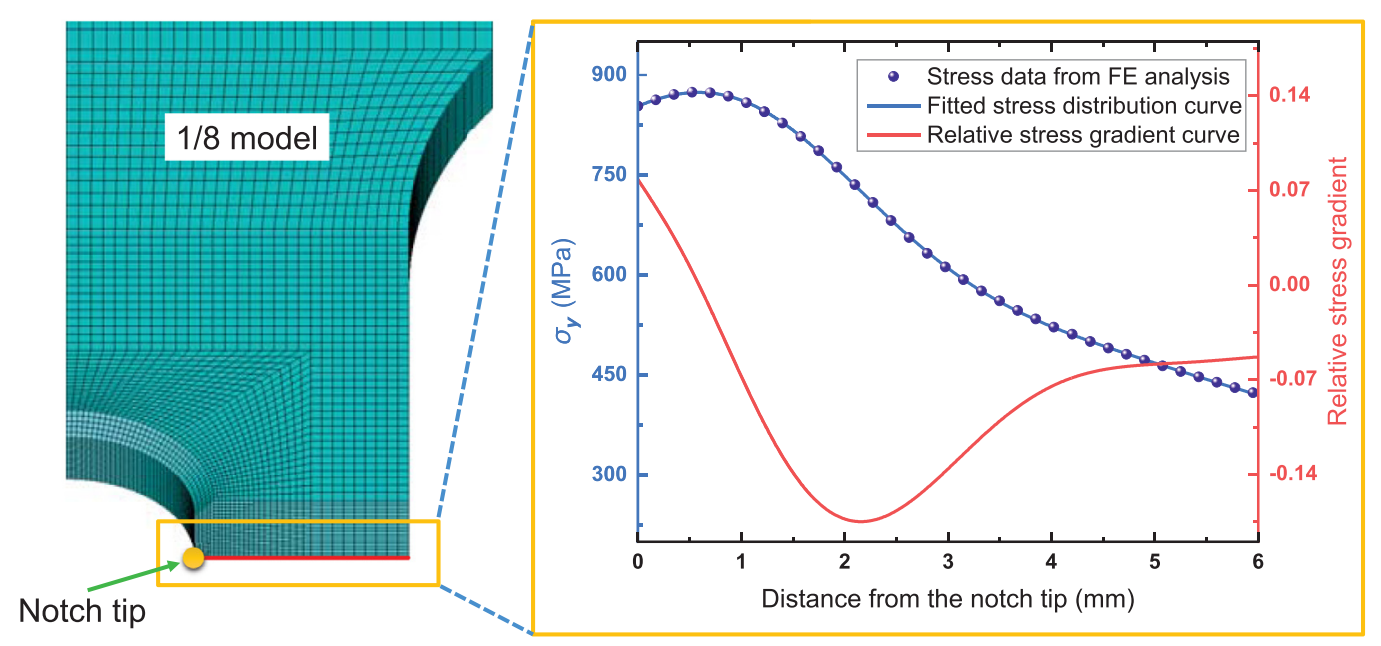

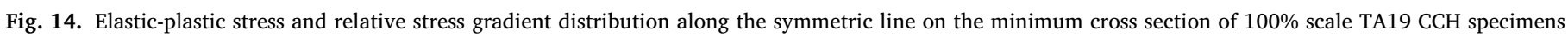
with a $536.54 \mathrm{MPa}$ nominal net section stress. 


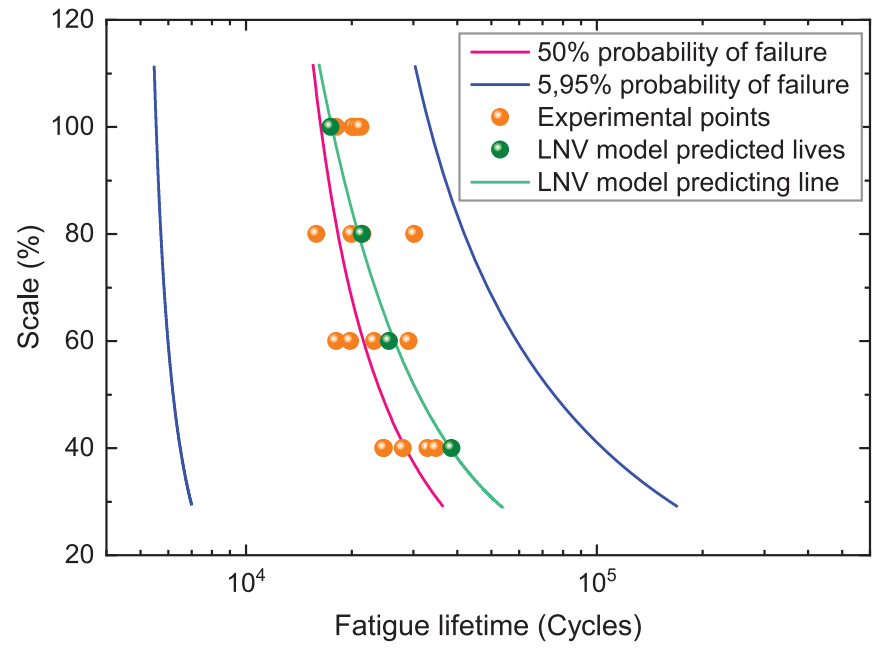

Fig. 16. Comparison of experimental and predicted probabilistic lifetimes for different scales of TA19 CCH specimens using the proposed probabilistic framework.

Table 7

Comparison between average absolute errors using proposed model and LNV model (\%).

\begin{tabular}{lllll}
\hline Scale (\%) & 100 & 80 & 60 & 40 \\
\hline LNV model & 6.10 & 10.45 & 9.98 & 6.06 \\
Proposed model & 8.93 & 9.62 & 6.86 & 5.66 \\
\hline
\end{tabular}

tively. Specifically, the fitted LNV predicting line, which connects predicted values with smooth curve, has also been plotted in Fig. 16. Note that the proposed model overall presents better predictions than LNV model except the $100 \%$ scale case.

Finally, as mentioned by both Calvente et al. [15] and Mäde et al. [21], performing probabilistic fatigue analysis from a volume perspective for engineering components. On one hand, in fatigue failure process, not only crack initiation but also crack growth matters, considering the fatigue crack propagation phase by combining the volume size effect and the crack propagation law can be a feasible strategy. On the other hand, replacing the external subareas of certain generalized damage parameters with subvolumes is closer to reality, since cracks can be initiated from both surfaces and insides, which may better interpret the size effect. In practice, since full-scale testing of components/systems are normally costly and time-consuming, the probabilistic framework proposed in this work provides an alternative scheme to transfer the smallscale sample testing results to the large-scale ones. More experiments on notched specimens with different scales are expected to further verify the robustness of the proposed framework for notch fatigue analysis.

\section{Conclusions}

In this study, a probabilistic framework based on the generalized local model further considering multiaxial stress and stress gradient is developed. In particular, this framework intends to achieve extrapolation of fatigue behaviour of large-scale structures using experimental data of small-scale specimens collected in laboratory. The main results are summarized as follows:

(1) For fatigue failure analysis of notched components, both size effect, notch effect (inhomogeneous stress distribution) as well as multiaxial stress state exert significant influences.

(2) On the basis of the Calvente's model, by integrating the Weibull probabilistic fatigue model and the generalized local model, a probabilistic framework considering multiaxial stress and inhomogeneous stress distribution is proposed by coupling the SWT model with the effective stress concept.

(3) By utilizing experimental data of TA19 notched specimens with different scales for model verification, the predicted lifetime, deduced based on fatigue properties collected from smooth specimens, corresponding to the $50 \%$ failure probability agree well with experimental results.

(4) The proposed model provides a promising way to predict the fatigue strength of arbitrary structures, irrespective of their geometries, dimensions as well as stress states, but experiments on more typical notched specimens with different scales are desired to further validate its robustness.

\section{Declaration of Competing Interest}

The authors declare that they have no known competing financial interests or personal relationships that could have appeared to influence the work reported in this paper.

\section{CRediT authorship contribution statement}

Ding Liao: Conceptualization, Methodology, Writing - original draft. Shun-Peng Zhu: Methodology, Data curation, Supervision. Behrooz Keshtegar: Software, Validation. Guian Qian: Visualization, Writing - review \& editing. Qingyuan Wang: Supervision, Writing - review \& editing.

\section{Acknowledgement}

Financial support of the National Natural Science Foundation of China (No. 11972110 and 11672070), Sichuan Provincial Key Research and Development Program (No. 2019YFG0348), Science and Technology Program of Guangzhou, China (No. 201904010463), Fundamental Research Funds for the Central Universities (No. ZYGX2019J040) and Opening funds of State Key Laboratory of Nonlinear Mechanics, Institute of Mechanics, Chinese Academy of Sciences and Key Laboratory of Deep Earth Science and Engineering (Sichuan University), Ministry of Education (No. DESE201901) are acknowledged. In particular, the authors gratefully acknowledge the IEMES Group from University of Oviedo, Spain for their software support in fatigue data analysis and Professor Dianyin Hu from Beihang University, China for fatigue data of TA19 specimens.

\section{References}

[1] Berto F, Lazzarin P, Tovo R. Multiaxial fatigue strength of severely notched cast iron specimens. Int J Fatigue 2014;67:15-27.

[2] Berto F, Campagnolo A. Multiaxial fatigue strength of severely notched titanium grade 5 alloy. Frat ed Integrità Strutt 2015;9(33):229-37.

[3] Masoudi Nejad R, Farhangdoost K, Shariati M, Moavenian M. Stress intensity factors evaluation for rolling contact fatigue cracks in rails. Tribol Trans 2017;60(4):645-52.

[4] Liao D, Zhu SP, de JAF, Correia O, De Jesus AMP, Calçada RAB. Computational framework for multiaxial fatigue life prediction of compressor discs considering notch effects. Eng Fract Mech 2018;202:423-35.

[5] Taddesse AT, Zhu SP, Liao D, Keshtegar B. Cyclic plastic zone-based notch analysis and damage evolution model for fatigue life prediction of metals. Mater Des 2020;191:108639.

[6] Berto F, Lazzarin P, Yates JR. Multiaxial fatigue of V-notched steel specimens: a non-conventional application of the local energy method. Fatigue Fract Eng Mater Struct 2011;34(11):921-43.

[7] Gates NR, Fatemi A. Notch deformation and stress gradient effects in multiaxial fatigue. Theor Appl Fract Mech 2016;84:3-25.

[8] Susmel L, Taylor D. A novel formulation of the theory of critical distances to estimate lifetime of notched components in the medium-cycle fatigue regime. Fatigue Fract Eng Mater Struct 2007;30(7):567-81.

[9] Ince A, Bang DJ. Deviatoric Neuber method for stress and strain analysis at notches under multiaxial loadings. Int J Fatigue 2017;102:229-40.

[10] Ye DY, Hertel O, Vormwald M. A unified expression of elastic-plastic notch stress-strain calculation in bodies subjected to multiaxial cyclic loading. Int J Solids Struct. 2008;45(24):6177-89. 
[11] Masoudi Nejad R. Using three-dimensional finite element analysis for simulation of residual stresses in railway wheels. Eng Fail Anal 2014;45:449-55.

[12] Nikishkov GP, Matvienko YG. Specimen thickness effect on elastic-plastic constraint parameter A. Frat ed Integrità Strutt 2015;9(33):73-9.

[13] Wang RQ, Li D, Hu DY, Meng FC, Liu H, Ma QH. A combined critical distance and highly-stressed-volume model to evaluate the statistical size effect of the stress concentrator on low cycle fatigue of TA19 plate. Int J Fatigue 2016;95:8-17.

[14] Ai Y, et al. Probabilistic modeling of fatigue life distribution and size effect of components with random defects. Int J Fatigue 2019;126:165-73.

[15] Muñiz-Calvente M, De Jesus AMP, de JAF, Correia O, Fernández-Canteli AC. A methodology for probabilistic prediction of fatigue crack initiation taking into account the scale effect. Eng Fract Mech 2017;185:101-13.

[16] Shariati M, Mohammadi E, Masoudi Nejad R. Effect of a new specimen size on fatigue crack growth behavior in thick-walled pressure vessels. Int J Press Vessel Pip 2017;150:1-10.

[17] Zhou ZY, Tong ZF, Qian GA, Berto F. Specimen size effect on the ductile-brittle transition reference temperature of A508-3 steel. Theor Appl Fract Mech 2019;104:102370

[18] Leitner M, Vormwald M, Remes H. Statistical size effect on multiaxial fatigue strength of notched steel components. Int J Fatigue 2017;104:322-33.

[19] Zhu SP, Foletti S, Beretta S. Evaluation of size effect on strain-controlled fatigue behavior of a quench and tempered rotor steel: Experimental and numerical study. Mater Sci Eng A 2018;735:423-35.

[20] Lin YC, Wen DX, Huang YC, Chen XM, Chen XW. A unified physically based constitutive model for describing strain hardening effect and dynamic recovery behavior of a Ni-based superalloy. J Mater Res 2015;30(24):3784-94.

[21] Mäde L, Schmitz S, Gottschalk H, Beck T. Combined notch and size effect modeling in a local probabilistic approach for LCF. Comput Mater Sci 2018;142:377388.

[22] Zhu SP, Liu YH, Liu Q, Yu ZY. Strain energy gradient-based LCF life prediction of turbine discs using critical distance concept. Int J Fatigue 2018;113:33-42.

[23] Jiang YQ, Lin YC, Zhang XY, Chen C, Wang QW, Pang GD. Isothermal tensile deformation behaviors and fracture mechanism of Ti-5Al-5Mo-5V-1Cr-1Fe alloy in $\beta$ phase field. Vacuum 2018;156:187-97.

[24] Lin YC, et al. Effects of initial microstructures on hot tensile deformation behaviors and fracture characteristics of Ti-6Al-4V alloy. Mater Sci Eng A 2018;711:293-302.

[25] Zhu SP, Xu S, Hao MF, Liao D, Wang QY. Stress-strain calculation and fatigue life assessment of V-shaped notches of turbine disk alloys. Eng Fail Anal. 2019;106:104187

[26] Liao D, Zhu SP. Energy field intensity approach for notch fatigue analysis. Int J Fatigue 2019;127:190-202.

[27] Li YB, et al. Weibull stress analysis in local approach to fracture. Theor Appl Fract Mech 2019;104:102379.

[28] Wu SC, Luo Y, Shen Z, Zhou LC, Zhang WH, Kang GZ. Collaborative crack initiation mechanism of 25CrMo4 alloy steels subjected to foreign object damages. Eng Fract Mech 2020;225:106844.

[29] Makkonen M. Notch size effects in the fatigue limit of steel. Int J Fatigue 2002;25(1):17-26

[30] Ai Y, Zhu SP, Liao D, de JAF, Correia O, De Jesus AMP, Keshtegar B. Probabilistic modelling of notch fatigue and size effect of components using highly stressed volume approach. Int J Fatigue 2019;127:110-19.

[31] Susmel L. The theory of critical distances: a review of its applications in fatigue. Eng Fract Mech 2008;75(7):1706-24.

[32] Liao D, Zhu SP, Qian GA. Multiaxial fatigue analysis of notched components using combined critical plane and critical distance approach. Int J Mech Sci 2019;160:38-50.

[33] Baumgartner J, Lipp K, Bruder T, Kaufmann H. Design methods for reliable fatigue assessment of PM components. Materwiss Werksttech 2011;42(10):894-903.

[34] Hu Z, Berto F, Susmel L. The strain energy density to estimate lifetime of notched components subjected to variable amplitude fatigue loading. Frat ed Integrità Strutt. 2019;13(47):383-93.

[35] Yao WX. Stress field intensity approach for predicting fatigue life. Int J Fatigue 1993;15(3) 246-246.

[36] Qylafku G, Azari Z, Kadi N, Gjonaj M, Pluvinage G. Application of a new model proposal for fatigue life prediction on notches and key-seats. Int J Fatigue 1999;21(8):753-60.

[37] Liao D, Zhu SP, de JAF, Correia O, De Jesus AMP, Berto F. Recent advances on notch effects in metal fatigue: A review. Fatigue Fract Eng Mater Struct 2020;43(4):637-59.

[38] Weibull W. Zur Abhängigkeit der Festigkeit von der Probengröße. Ingenieur-Archiv 1959;28(1):360-2.

[39] Lei WS, Qian GA, Yu ZS, Berto F. Statistical size scaling of compressive strength of quasi-brittle materials incorporating specimen length-to-diameter ratio effect. Theor Appl Fract Mech 2019;104:102345.

[40] Qian GA, Lei WS, Yu ZS, Berto F. Statistical size scaling of breakage strength of irregularly-shaped particles. Theor Appl Fract Mech 2019;102:51-8.

[41] Kaffenberger M, Vormwald M. Considering size effects in the notch stress concept for fatigue assessment of welded joints. Comput Mater Sci 2012;64:71-8.

[42] Muñiz-Calvente M, Fernández-Canteli AC, Shlyannikov V, Castillo E. Probabilistic weibull methodology for fracture prediction of brittle and ductile materials. Appl Mech Mater 2015;784:443-51.

[43] Lin YC, Zhao CY, Chen MS, Chen DD. A novel constitutive model for hot deformation behaviors of Ti-6Al-4V alloy based on probabilistic method. Appl Phys A Mater Sci Process 2016;122(8):716.
[44] Zhu SP, Huang HZ, Peng W, Wang HK, Mahadevan S. Probabilistic physics of failure-based framework for fatigue life prediction of aircraft gas turbine discs under uncertainty. Reliab Eng Syst Saf 2016;146:1-12

[45] Raposo P, de JAF, Correia O, De Jesus AMP, Calçada RAB. Probabilistic fatigue S-N curves derivation for notched components. Frat ed Integrità Strutt 2017;42(12):105-18.

[46] Zhu SP, Liu Q, Peng WW, Zhang XC. Computational-experimental approaches for fatigue reliability assessment of turbine bladed disks. Int $\mathrm{J}$ Mech Sci 2018;142-143:502-17.

[47] Zhu SP, Liu Q, Zhou J, Yu ZY. Fatigue reliability assessment of turbine discs under multi-source uncertainties. Fatigue Fract Eng Mater Struct 2018;41(6):12911305.

[48] Zhu SP, Liu Q, Lei Q, Wang QY. Probabilistic fatigue life prediction and reliability assessment of a high pressure turbine disc considering load variations. Int J Damage Mech 2018;27(10):1569-88.

[49] Liu R, Chen PW, Zhang XT, Zhu SP. Non-shock ignition probability of octahydro-1,3,5,7-tetranitro-tetrazocine-based polymer bonded explosives based on microcrack stochastic distribution. Propellants, Explos Pyrotech 2020;45(4):568-80.

[50] Meng D, Yang S, Zhang Y, Zhu SP. Structural reliability analysis and uncertainties-based collaborative design and optimization of turbine blades using surrogate model. Fatigue Fract Eng Mater Struct 2019;42(6):1219-27.

[51] Zhu SP, Hao YZ, Liao D. Probabilistic modeling and simulation of multiple surface crack propagation and coalescence. Appl Math Model 2020;78:383-98.

[52] Castillo E, Fernández-Canteli AC. A Unified Statistical Methodology For Modeling Fatigue Damage. Netherlands: Springer; 2009.

[53] Heckel K, Köhler J, München T. Experimentelle untersuchung des statistischen Größeneinflusses im dauerschwingversuch an ungekerbten stahlproben. Materwiss Werksttech 1975;6(2):52-4.

[54] Castillo E, López-Aenlle M, Ramos A, Fernández-Canteli AC, Kieselbach R, Esslinger V. Specimen length effect on parameter estimation in modelling fatigue strength by Weibull distribution. Int J Fatigue 2006;28(9):1047-58.

[55] Lei WS. A generalized weakest-link model for size effect on strength of quasi-brittle materials. J Mater Sci 2018;53(2):1227-45.

[56] Carpinteri A, Spagnoli A, Vantadori S. Size effect in S-N curves: a fractal approach to finite-life fatigue strength. Int J Fatigue 2009;31(5):927-33.

[57] Walker K. The effect of stress ratio during crack propagation and fatigue for 2024-T3 and 7075-T6 aluminum," in effects of environment and complex load history on fatigue life. ASTM Int 2009.

[58] Liu X, Wang YR, Tian AM, Shi L. A life prediction method for size effects on notched fatigue. J Aerosp Power 2017;32(2):429-37.

[59] Schmitz S, Seibel T, Beck T, Rollmann G, Krause R, Gottschalk H. A probabilistic model for LCF. Comput Mater Sci 2013;79:584-90.

[60] Mäde L, Gottschalk H, Schmitz S, Beck T, Rollmann G. Probabilistic LCF risk evaluation of a turbine vane by combined size effect and notch support modeling. ASME Turbo Expo 2017: Turbomachinery technical conference and exposition. american society of mechanical engineers; 2017.

[61] Wang RQ, Liu H, Hu DY, Li D, Mao JX. Evaluation of notch size effect on LCF life of TA19 specimens based on the stress gradient modified critical distance method. Fatigue Fract Eng Mater Struct 2018;41(8):1794-809.

[62] Schijve J. Statistical distribution functions and fatigue of structures. Int J Fatigue 2005;27(9):1031-9.

[63] de JAF, Correia O, et al. Generalized probabilistic model allowing for various fatigue damage variables. Int J Fatigue 2017;100:187-94.

[64] Shirani M, Härkegård G. Fatigue life distribution and size effect in ductile cast iron for wind turbine components. Eng Fail Anal 2011;18:12-24.

[65] Shirani M, Härkegård G. Large scale axial fatigue testing of ductile cast iron for heavy section wind turbine components. Eng Fail Anal 2011;18:1496-510.

[66] M. Muñiz-Calvente, "The generalized local model: A methodology for probabilistic assessment of fracture under different failure criteria," Universidad de Oviedo, 2017.

[67] Jia D, Huang XC, Mo J. A method to determine stress triaxiality of notched specimens from tensile tests. Proceeding of the chinese conference on computational mechanics 2012 (CCCM2012); 2012.

[68] Gong JG, Gong C, Xuan FZ, Chen HF. Notch effect on structural strength of components at elevated temperature under creep, fatigue, and creep-fatigue loading conditions. J Press Vessel Technol 2019;141:05080101-14.

[69] Smith KN, Watson P, Topper TH. A stress-strain function for the fatigue of metals. J Mater 1970;5:767-78.

[70] Socie DF, Marquis GB. Multiaxial Fatigue. Warrendale: Society of Automotive Engineers, Inc.; 2000.

[71] Shawki GSA, Mashhour AA. A fatigue-testing machine for combined bending and torsion. Exp Mech 1974;14(5):196-201.

[72] Kurek M, Lagoda T, Katzy D. Comparison of fatigue characteristics of some selected materials. Mater Test 2014;56(2):92-5.

[73] Qylafku G, Azari Z, Gjonaj M, Pluvinage G. On the fatigue failure and life prediction for notched specimens. Mater Sci 1998;34(5):604-18.

[74] Ostash OP, Panasyuk VV. Fatigue process zone at notches. Int J Fatigue 2001;23(7):627-36.

[75] Pluvinage G. Notch effects in fatigue and fracture. Notch Eff Fatigue Fract 2001.

[76] Li D, Hu DY, Wang RQ, Ma QH, Liu H. A non-local approach for probabilistic assessment of LCF life based on optimized effective-damage-parameter. Eng Fract Mech 2018;199:188-200.

[77] China Aeronautical Materials Handbook Editorial Committee. China Aeronautical Materials Handbook Vol. 4 Titanium Alloy \& Copper Alloy. 2nd ed. Beijing: China Standards Press; 2002. 